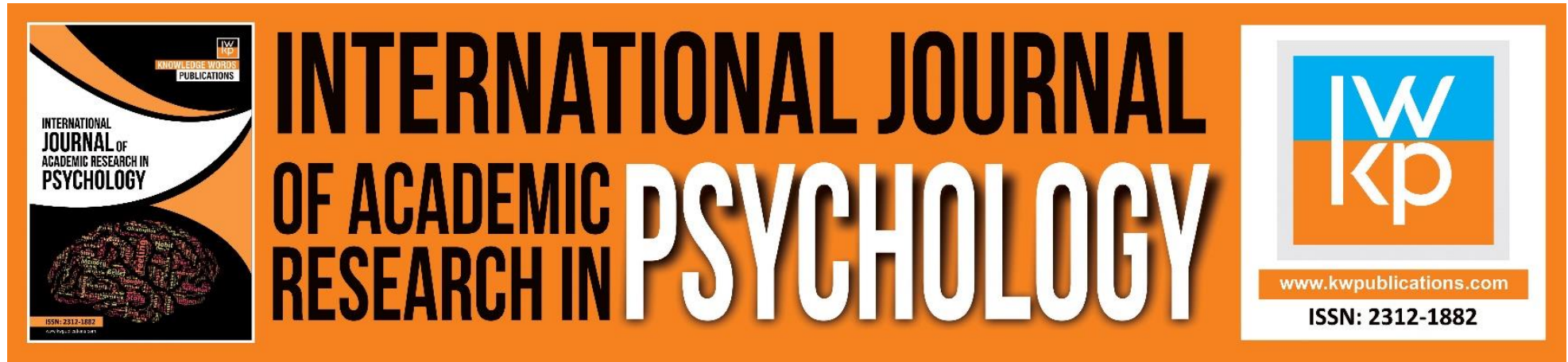

\title{
The Relationship between Resiliency with Self- Efficacy and Stress in Iranian Female High School Students
}

\section{Golnar Fayazi, Fatemeh Bagherian}

To Link this Article: http://dx.doi.org/10.46886/IJARP/v5-i1/6095

DOI: $10.46886 / I J A R P / v 5-i 1 / 6095$

Received: 01 February 2018, Revised: 09 March 2018, Accepted: 16 April 2018

Published Online: 28 April 2018

In-Text Citation: (Fayazi \& Bagherian, 2019)

To Cite this Article: Fayazi, G., \& Bagherian, F. (2019). The Relationship between Resiliency with Self- Efficacy and Stress in In Iranian Female High School Students. International Journal of Academic Research in Psychology, 5(1), 10-17.

Copyright: (c) 2018 The Author(s)

Published by Knowledge Words Publications (www.kwpublications.com)

This article is published under the Creative Commons Attribution (CC BY 4.0) license. Anyone may reproduce, distribute, translate and create derivative works of this article (for both commercial and non-commercial purposes), subject to full attribution to the original publication and authors. The full terms of this license may be seen at: http://creativecommons.org/licences/by/4.0/legalcode

Vol. 5, No. 1, 2018, Pg. 10 - 17

Full Terms \& Conditions of access and use can be found at https://kwpublications.com/pages/detail/publication-ethics 


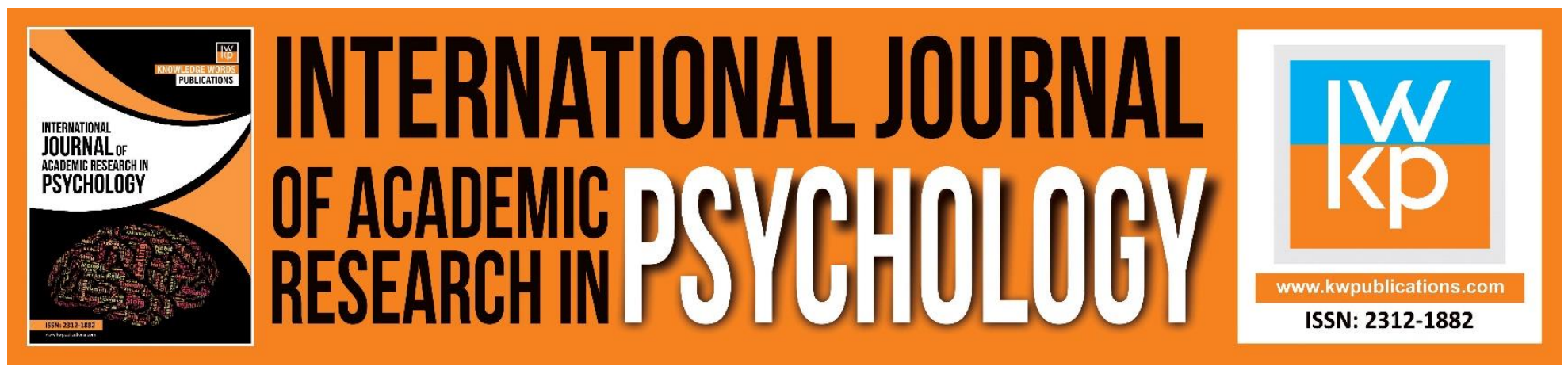

\title{
The Relationship between Resiliency with Self- Efficacy and Stress in Iranian Female High School Students
}

\section{Golnar Fayazi, Fatemeh Bagherian}

${ }^{1} \mathrm{M}$.A in Family Therapy Psychology, Shahid Beheshti University, Tehran, Iran, ${ }^{2}$ Associate Professor of Psychology, Shahid Beheshti University, Tehran, Iran, Department of Family Therapy Psychology,

Shahid Beheshti University, Tehran.

\begin{abstract}
Relationships between resiliency with self- efficacy and stress were investigated in Iranian female high school students in Grades 10 to $12(\mathrm{~N}=176)$. Research tools included the General self-efficacy (GSE), Depression, anxiety and stress scale- 21 and Family Resilience Assessment Scale (FRAS). The findings of this study indicated that there was a significant positive correlation between resiliency with self- efficacy and stress $(P<0.05)$. According to the findings of this study, there is a positive and significant relationship between resiliency with self- efficacy and stress in Iranian female high school. Considering the findings of this research can be effective in improving the lives of high school students and the emotional atmosphere of their families. On the other hand, the findings of this study can be used in designing and feasibility of educational protocols to reduce the problems and prevent the creation of a crisis in the life of Iranian adolescents for families.
\end{abstract}

Keywords: Resiliency, Self- Efficacy, High School Students.

\section{Introduction}

A compelling body of epidemiologic research indicates that exposure to stressful events contributes to poor health and health disparities over the life course (James, 2009; Miller, Chen \& Cole, 2009). "Stress" refers to any threat or challenge to homeostasis (McEwen, 2013), and includes a broad range of exposures such as prenatal insults (Hilmert et al., 2008), early life adversity (Miller, Chen, \& Parker, 2011), work (e.g., job strain), finances (e.g., poverty, food insecurity), interpersonal events (e.g., divorce, social isolation), trauma (e.g., emotional, physical, or sexual abuse), and experiences of discrimination (Abdou et al., 2016). While the neurobiological stress response (e.g., hypothalamicpituitary-adrenal (HPA)-axis, sympathetic nervous system) is well-suited for addressing acute stressors, it is hypothesized that repeated, chronic activation of the body's stress response (commonly operationalized as "allostatic load," "weathering," and related constructs) contributes to the development of cardiovascular and metabolic conditions in mid- and late-life (Geronimus, 1992; McEwen \& Seeman, 1999; Miller et al., 2011). Moreover, General self-efficacy is the belief in one's 
competence to cope with a broad range of stressful or challenging demands, whereas specific selfefficacy is constrained to a particular task at hand (Luszczynska, Scholz and Schwarzer, 2005). The stronger the students' belief in self-efficacy the stronger are their cognitive growth. As stated by Bandura and Locke (2003), perceived self-efficacy is apprehended as an important contributor to academic accomplishments, achievement enhancement and many aspects of well-being. The relations between general self-efficacy, stress appraisal, well-being and achievement in a broad range of stressful or challenging encounters were explored by Luszczynska, Gutierrez-Dona and Schwarzer (2005) across several countries. Social cognitive theory (Bandura and Locke, 2003) expects that selfefficacy positively influences the performance in any kind of task. Bandura (1997, Bandura and Locke, 2003) mention self-efficacy as a causal contributor to human well-being and accomplishments. Also Kebza (2005) considers self-efficacy to be one of the main components of well-being and mental health. Self-efficacy represents a way to self-control individual's emotions which can bring multiple advantages in the area of stress. Self-efficacy can explain therefore the vulnerability we show when faced with stressful situations, but it can also be a helping hand for the cognitive activation of stress theory (CATS) through conceptual resemblance regarding the anticipation mechanism for the oscillatory result of an action. Therefore if an individual perceives a task after it's cognitive evaluation and according to his/her experience as being a difficult one, the answer he/she will get to the task will trigger an alert which will increase the level of stress. We can therefore say that a positive or negative evaluation of a situation may represent an impulse or a break in overcoming obstacles thus influencing the level of stress self-perceived and biological. Also, Resilience is the ability of an individual to positively adjust to adversity, and can be applied to building personal strengths in nurses through strategies such as: building positive and nurturing professional relationships; maintaining positivity; developing emotional insight; achieving life balance and spirituality; and, becoming more reflective. While much is known about the direct effects of stress exposure on health, there has been less focus on how the intersection between stress and coping behaviors (i.e., efforts to self-regulate the body's stress response) relates to health and health disparities (Ellis \& Giudice, 2014; Mezuk et al., 2013). Under the conceptualization of stress as a direct cause of poor physical health, behaviors are treated as confounders (i.e., correlates of stress and causally related to health, but not part of the pathway linking the two (Umberson, Liu \& Reczek, 2008). In sum, a growing body of research indicates that the relationships among stress exposure, stress reactivity, and health behaviors are intrinsically linked in two important ways: (1) Stress exposure impacts the likelihood of engaging in health behaviors, and these behaviors, in turn, impact physiological reactivity to subsequent stressors; and (2) These behaviors engage reinforcing (e.g., dopaminergic and opioid) pathways in the brain, which are also connected to the HPA-axis and related stress-response systems. Thus, in the short-term, these health behaviors can serve as effective stress-coping strategies and preserve mental health, just as traditional approach-oriented coping strategies are known to do. However, unlike these traditional coping strategies, over the long-term behaviors such as smoking, excessive alcohol use, and poor diet contribute to disparities in physical health (Lantz et al., 1998). Regarding the effect of self-efficacy, stress and resilience in increasing life satisfaction and increasing emotional excitement, therefore the present study aimed to investigate the Relationship Between resiliency with self- efficacy and stress in in Iranian female high school students 
INTERNATIONAL JOURNAL OF ACADEMIC RESEARCH IN PSYCHOLOGY

Vol. 5, No. 1, 2018, E-ISSN: 2312-1882 @ 2018 KWP

\section{Material and Methods \\ Participants}

In this correlational study, the 176 female students aged between 14 and 17 years old of high school of Tehran were selected through the use of multi- cluster sampling. Of these, $36.9 \%$ at the first grade, $40.9 \%$ in the second grade and $22.2 \%$ in the third grade high school in the experimental science $(60 \%)$ and mathematical (40\%) fields studied, and in terms of the level of education of parents $4.7 \%$ diploma, $42.6 \%$ bachelor's, $25 \%$ masters and $23.9 \%$ doctoral, as well as $96.6 \%$ employed and $3.4 \%$ unemployed.

\section{Data Analysis Method}

In this study descriptive statistics was applied for analysis of the demographic data. For inferential statistics, data were analyzed using Statistical Package for Social Sciences (SPSS) version 22. All data collection forms were given serial numbers. Data were entered, checked for data entry errors, explored and cleaned. The researcher used alpha $(\alpha)$ at 0.05 and confidence interval of $95 \%$. Instrument

\section{General Self-efficacy (GSE)}

The SGSES (Sherer et al., 1982) is a Likert format 17-item scale (example of items include: "When I make plans, I am certain I can make them work ", "I give up easily", "I am a self-reliant person", "I avoid facing difficulties"). The response format is a 5 -point scale ( $1=$ strongly disagree, $5=$ strongly agree). Sum of item scores reflects general self-efficacy. The higher the total score is, the more selfefficacious the respondent. Sherer et al. Higher score indicates stronger self-efficiency, and lower score indicates weaker self- efficiency.

Depression, anxiety and stress scale- 21: The DASS-21 is the shortened version of the DASS developed by Lovibond and Lovibond. to assess symptoms of depression, anxiety and stress among adults. In the DASS-21. the respondent is asked to think about their experiences in the past seven days and to judge how each statement applied to them. There are 21 items in this scale with four response options: 0 "Did not apply to me at all-Never", 1 "Applied to me to some degree, or some of the time-Sometimes", 2 "Applied to me to a considerable degree, or a good part of time-Often" to 3 "Applied to me very much, or most of the time-Almost always". Scores on three subscales naming DASS-21-Depression (DASS-21-D), DASS-21-Anxiety (DASS-21-A) and Stress (DASS-21-S) can then be calculated. There are seven items in each of the subscales; the score of which ranges from 0 to 21. The DASS-21 has been validated for use among iranian samples.

Family Resilience Assessment Scale (FRAS): The FRAS was developed by Sixbey (2005) to measure family resilience and was based on Walsh's Family Resilience Model. The FRAS measures 66 family resilience on six factors: family communication and problem-solving, utilizing social and economic resources, maintaining a positive outlook, family connectedness, family spirituality, and ability to make meaning of adversity (Sixbey, 2005). Reliability for the FRAS is high, with a Cronbach's alpha of .96 for the total scale (Sixbey, 2005). Scores on the FRAS can range between 66 and 264; lower scores indicate little resilience within the family, while higher scores indicate high levels of resilience in the family. 


\section{INTERNATIONAL JOURNAL OF ACADEMIC RESEARCH IN PSYCHOLOGY}

Vol. 5, No. 1, 2018, E-ISSN: 2312-1882 @ 2018 KWP

\section{Results}

Table 1 indicates the correlation coefficient between the self-efficacy, family resilience and stress

Table 1: the correlation coefficient between the self-efficacy, family resilience and stress

\begin{tabular}{|c|c|c|c|c|c|c|c|c|c|c|c|}
\hline Variable & $M$ & SD & 1 & 2 & 3 & 4 & 5 & 6 & 7 & 8 & 9 \\
\hline 1. stress & $17 / 56$ & $\begin{array}{c}10 / 8 \\
5\end{array}$ & - & & & & & & & & \\
\hline $\begin{array}{l}\text { 2. family } \\
\text { resilience }\end{array}$ & $\begin{array}{c}186 / 8 \\
9\end{array}$ & $\begin{array}{c}20 / 4 \\
8\end{array}$ & $\begin{array}{c}0 / 44^{*} \\
-*\end{array}$ & - & & & & & & & \\
\hline $\begin{array}{l}\text { 3. Family } \\
\text { communicati } \\
\text { on and } \\
\text { problem- } \\
\text { solving }\end{array}$ & $77 / 82$ & $\begin{array}{c}12 / 6 \\
7\end{array}$ & $\begin{array}{c}0 / 43^{*} \\
-*\end{array}$ & $\begin{array}{l}0 / 92^{*} \\
*\end{array}$ & - & & & & & & \\
\hline $\begin{array}{l}\text { 4. utilizing } \\
\text { social and } \\
\text { economical } \\
\text { resources, } \\
5 \text {. }\end{array}$ & $18 / 85$ & $4 / 46$ & $\begin{array}{c}0 / 25^{*} \\
-*\end{array}$ & $\begin{array}{l}0 / 54^{*} \\
\quad *\end{array}$ & $\begin{array}{c}0 / 33^{*} \\
*\end{array}$ & - & & & & & \\
\hline $\begin{array}{l}\text { maintaining a } \\
\text { positive } \\
\text { outlook, } \\
6 \text {. family }\end{array}$ & $18 / 77$ & $3 / 06$ & $\begin{array}{c}0 / 37^{*} \\
-*\end{array}$ & $\begin{array}{l}0 / 77^{*} \\
*\end{array}$ & $\begin{array}{c}0 / 74^{*} \\
*\end{array}$ & $\begin{array}{c}0 / 27^{*} \\
*\end{array}$ & - & & & & \\
\hline $\begin{array}{l}\text { connectedne } \\
\text { ss, }\end{array}$ & $15 / 53$ & $1 / 97$ & 0/08 & 0/01 & $-0 / 13$ & $0 / 03$ & $-0 / 14$ & - & & & \\
\hline $\begin{array}{l}\text { 7. family } \\
\text { spirituality } \\
\text { 8. and ability }\end{array}$ & $9 / 02$ & $2 / 27$ & $-0 / 14$ & $\begin{array}{l}0 / 33^{*} \\
*\end{array}$ & $0 / 18^{*}$ & $0 / 34$ & 0/07 & $\begin{array}{c}0 / 00 \\
3\end{array}$ & - & & \\
\hline $\begin{array}{l}\text { to make } \\
\text { meaning of } \\
\text { adversity }\end{array}$ & $8 / 94$ & $1 / 47$ & $-0 / 13$ & $\begin{array}{l}0 / 43^{*} \\
*\end{array}$ & $\begin{array}{c}0 / 33^{*} \\
*\end{array}$ & $0 / 14$ & $\begin{array}{c}0 / 30^{*} \\
*\end{array}$ & $0 / 08$ & $\begin{array}{c}0 / 0 \\
8\end{array}$ & - & \\
\hline $\begin{array}{l}\text { 9. self- } \\
\text { efficacy }\end{array}$ & $63 / 20$ & $\begin{array}{c}10 / 9 \\
0 \\
\end{array}$ & $\begin{array}{c}0 / 51^{*} \\
-* \\
\end{array}$ & $\begin{array}{c}0 / 44^{*} \\
* \\
\end{array}$ & $\begin{array}{c}0 / 50^{*} \\
* \\
\end{array}$ & 0/04 & $\begin{array}{c}0 / 49 * \\
* \\
\end{array}$ & $\begin{array}{c}0 / 14 \\
- \\
\end{array}$ & $\begin{array}{c}0 / 0 \\
6 \\
\end{array}$ & $\begin{array}{c}0 / 19 * \\
* \\
\end{array}$ & - \\
\hline
\end{tabular}

According to Table 1, Correlation between stress and self-efficacy (-0.51) was statistically significant. Also, the correlation between stress and resiliency was observed $(-0.44)$, which is statistically. The observed correlation between self-efficacy and resiliency $(0.44)$ is statistically significant $(P<0 / 01)$. Step-by-step regression was use to predict and explain the variance of stress and self-efficacy based on the family resilience (Table 2 ). 
INTERNATIONAL JOURNAL OF ACADEMIC RESEARCH IN PSYCHOLOGY

Vol. 5, No. 1, 2018, E-ISSN: 2312-1882 @ 2018 KWP

Table 3: Multiple Regression Results: Model 1 Summary

\begin{tabular}{cccccc}
\hline step & SS & MS & df & F & Sig \\
\hline \multirow{2}{*}{1} & $14575 / 26$ & $14575 / 26$ & 1 & $43 / 06$ & $0 / 01$ \\
& $58893 / 68$ & $338 / 46$ & 174 & & \\
2 & $19294 / 77$ & $9647 / 39$ & 1 & $30 / 80$ & $0 / 01$ \\
& $54174 / 17$ & $313 / 14$ & 174 & & \\
\hline
\end{tabular}

Table 2: the results of step-by-step regression analysis based on the Stress and self-efficacy variables through family resilience

\begin{tabular}{lcccccc}
\hline step & variable & $\mathrm{R}$ & $\mathrm{R}^{2}$ & $\mathrm{SE}$ & $\mathrm{B}$ & Beta \\
\hline 1 & $\begin{array}{c}\text { Stress } \\
\text { self- }\end{array}$ & $0 / 44$ & $0 / 19$ & $0 / 12$ & $-0 / 84$ & $-0 / 44$ \\
2 & $0 / 51$ & $0 / 26$ & $0 / 14$ & $0 / 55$ & $0 / 29$ \\
\hline
\end{tabular}

Table 2 indicates that stress in the first step explained 19 percent of changes in resiliency. Also In the second step, self- efficacy explained 26 percent of changes in family resiliency were significantly predicted.

\section{Discussion and Conclusion}

The purpose of this study was to investigate the relationship between resiliency with self- efficacy and stress in in Iranian female high school students. The results showed that there is a significant relationship between self- efficacy and stress in high school students. These results agreed with the findings of the studies by (Jackson et all, 2007; Winsett et all, 2010) Which showed that patients with higher self- efficacy had higher resiliency. In addition, the results have shown that individuals with high resilience under stressful conditions maintain their mental health and are better performance It's also agreed.Pinquart (2009)'s study that resilience prevents psychological problems in young people and protects them from the psychological effects of problematic events. As well as the results of the research, Noone and Hastings (2009) found that resiliency creates a reduction in work stress and increases the mental health of staff and teachers who interact with people with mental retardation and are aligned in one direction In explaining the results, it can be stated that resonance as a protective and important factor can play a decisive role in reducing stress in students In fact, high resilience can keep students in trouble and difficult situations and increase their mental health. On the other hand, high self-efficacy in students reflects more resilience in them, resulting in a reduction in stress and increased mental health and quality of life. One limitation of the current study was the sample size is low and includes high school girls. Therefore, it is recommended that in future studies and similar students with more boys and other educational levels should be used.

\section{Acknowledgments}

The authors thank the all students who participated in this research. 
INTERNATIONAL JOURNAL OF ACADEMIC RESEARCH IN PSYCHOLOGY

Vol. 5, No. 1, 2018, E-ISSN: 2312-1882 @ 2018 KWP

\section{References}

Abdou, C. M., Fingerhut, A. W., Jackson, J. S., \& Wheaton, F. (2016). Healthcare Stereotype Threat in Older Adults in the Health and Retirement Study. Am J Prev Med, 50(2), 191-198. doi:10.1016/j.amepre.2015.07.034.

Ellis, B. J., \& Del Giudice, M. (2014). Beyond allostatic load: rethinking the role of stress in regulating human development. Dev Psychopathol, 26(1), 1-20. doi:10.1017/s0954579413000849.

Hilmert, C. J., Schetter, C. D., Dominguez, T. P., Abdou, C., Hobel, C. J., Glynn, L., \& Sandman, C. (2008). Stress and blood pressure during pregnancy: racial differences and associations with birthweight. Psychosom Med, 70(1), 57-64. doi:10.1097/PSY.0b013e31815c6d96

Jackson, D., Firtko, A., \& Edenborough, M. (2007). Personal resilience as a strategy for surviving and thriving in the face of workplace adversity: a literature review. J Adv Nurs, 60(1), 1-9. doi:10.1111/j.1365-2648.2007.04412.x.

James, S. A. (2009). Epidemiologic research on health disparities: some thoughts on history and current developments. Epidemiol Rev, 31, 1-6. doi:10.1093/epirev/mxp010.

Lantz, P. M., House, J. S., Lepkowski, J. M., Williams, D. R., Mero, R. P., \& Chen, J. (1998). Socioeconomic factors, health behaviors, and mortality: results from a nationally representative prospective study of US adults. Jama, 279(21), 1703-1708.

McEwen, B. S. (2006). Protective and damaging effects of stress mediators: central role of the brain. Dialogues Clin Neurosci, 8(4), 367-381.

McEwen, B. S. (2013). The Brain on Stress: Toward an Integrative Approach to Brain, Body, and Behavior. Perspectives on psychological science : a journal of the Association for Psychological Science, 8(6), 673-675. doi:10.1177/1745691613506907.

McEwen, B. S., \& Seeman, T. (1999). Protective and damaging effects of mediators of stress. Elaborating and testing the concepts of allostasis and allostatic load. Ann N Y Acad Sci, 896, 30-47.

Melvin, K. C., Gross, D., Hayat, M. J., Jennings, B. M., \& Campbell, J. C. (2012). Couple functioning and post-traumatic stress symptoms in US Army couples: the role of resilience. Res Nurs Health, 35(2), 164-177. doi:10.1002/nur.21459.

Mezuk, B., Abdou, C. M., Hudson, D., Kershaw, K. N., Rafferty, J. A., Lee, H., \& Jackson, J. S. (2013). "White Box" Epidemiology and the Social Neuroscience of Health Behaviors: The Environmental Affordances Model. Society and mental health, 3(2), 10.1177/2156869313480892. doi:10.1177/2156869313480892.

Miller, G., Chen, E., \& Cole, S. W. (2009). Health psychology: developing biologically plausible models linking the social world and physical health. Annu Rev Psychol, 60, 501-524. doi:10.1146/annurev.psych.60.110707.163551

Miller, G. E., Chen, E., \& Parker, K. J. (2011). Psychological stress in childhood and susceptibility to the chronic diseases of aging: moving toward a model of behavioral and biological mechanisms. Psychol Bull, 137(6), 959-997. doi:10.1037/a0024768

Najafi, M., \& Foladjang, M. (2007). The Relationship Between Self- Efficacy and Mental Health Among High School Students.. CPAP, 1(22), 69-83.

Noone, S. J., \& Hastings, R. P. (2009). Building psychological resilience in support staff caring for people with intellectual disabilities: pilot evaluation of an acceptance-based intervention. $J$ Intellect Disabil, 13(1), 43-53. doi:10.1177/1744629509103519. 
Ong, A. D., Bergeman, C. S., Bisconti, T. L., \& Wallace, K. A. (2006). Psychological resilience, positive emotions, and successful adaptation to stress in later life. J Pers Soc Psychol, 91(4), 730-749. doi:10.1037/0022-3514.91.4.730.

Pinquart, M. (2009). Moderating effects of dispositional resilience on associations between hassles and psychological distress. Journal of Applied Developmental Psychology, 30(1), 53-60. doi:https://doi.org/10.1016/j.appdev.2008.10.005.

Seidi, M. S., Pour Ebrahim, T., Bagherian, F., \& Mansour, L. (2011). The relationship between spirituality and resilience of families, the quality of communication in family mediation. Scientific Journal Management System, 2(5), 63-79.

Sixbey, T. M. (2019). Development of the family resilience assessment scale to identify family resilience constructs [electronic resource].

Tugade, M. M., \& Fredrickson, B. L. (2004). Resilient individuals use positive emotions to bounce back from negative emotional experiences. Journal of personality and social psychology, 86(2), 320333. doi:10.1037/0022-3514.86.2.320.

Umberson, D., Liu, H., \& Reczek, C. (2008). Stress and health behaviors. In H. Turner, \& S. Schiemann (Eds.), Advances in life course research: stress processes across the life course. Oxford: England: Elsevier.

Winsett, R. P., Stender, S. R., Gower, G., \& Burghen, G. A. (2010). Adolescent self-efficacy and resilience in participants attending A diabetes camp. Pediatr Nurs, 36(6), 293-296; quiz 297. 